\title{
Clavicle Hook Depth and Impingement Syndrome-A Cause-Effect Relationship
}

\author{
Senthil Loganathan, Shenbaghavalli Thanikaimalai, Jambu Nageshwaran, Samuel Chittaranjan \\ Department of Orthopaedics, Sri Ramachandra University, Chennai, India \\ Email: shenscorp@gmail.com
}

How to cite this paper: Loganathan, S., Thanikaimalai, S., Nageshwaran, J. and Chittaranjan, S. (2017) Clavicle Hook Depth and Impingement Syndrome-A CauseEffect Relationship. Open Journal of Orthopedics, 7, 1-6.

http://dx.doi.org/10.4236/ojo.2017.71001

Received: November 21, 2016

Accepted: January 10, 2017

Published: January 13, 2017

Copyright $\odot 2017$ by authors and Scientific Research Publishing Inc. This work is licensed under the Creative Commons Attribution International License (CC BY 4.0).

http://creativecommons.org/licenses/by/4.0/

\begin{abstract}
Background: Clavicular hook plates are effective fixation devices for lateral end clavicle fractures and acromioclavicular joint dislocations and have been extensively used in the last decade. Although this plate achieves a high percentage of union, there are concerns about sub-acromial osteolysis and impingement of supraspinatus tendon. Objective: To show that impingement of supraspinatus tendon can be prevented by measuring the depth between acromion and supraspinatus tendon posteriorly and using hook plates of appropriate depth. Materials and Methods: We performed a prospective study on 25 patients with lateral end clavicle fractures and acromio clavicular joint disruptions by measuring the depth between posterior border of acromion and the superior border of supraspinatus at the point of application of hook plate. Fixation is then done by appropriate sized hook plate. Results: None of the patients had impingement of supraspinatus tendon. Five patients developed subacromial osteolysis which did not have any impact on shoulder function. Conclusion: There is a variation in anatomy of the acromion in different ethnic groups. Hence uniform sized hook plate will be inappropriate. A smaller hook depth is needed in south Asian population to prevent impingement.
\end{abstract}

\section{Keywords}

Hook Plate Clavicle, Hook Depth, Impingement

\section{Introduction}

Acromio-clavicular joint dislocations constitute for 3\% - 5\% of shoulder injuries [1] and lateral end clavicle fractures constitute $10 \%-15 \%$ of clavicle fractures [2]. Type 3 Acromio-Clavicular joint dislocations and type 2, 3 Neer lateral end clavicle fractures require operative management. Hook plate fixation has been reported to give good results by several authors. Supraspinatus impingement 
remains common complication with hook plate fixation [3]. There are variations in anatomy in posterior part of acromion in different patients. In our study, we sought to determine whether measuring the depth between acromion and supraspinatus tendon intraoperatively and fixing appropriate sized hook plates prevent the sub-acromial shoulder impingement.

\section{Materials and Methods}

This prospective study was done in SRMC from May 2010 to December 2015 after obtaining ethical clearance. We followed a total of 25 patients after obtaining informed consent for the study and publication of results and photos (15 men, 10 women) out of which 4 patients had lateral end clavicle fractures (NEER type 2 and 3) and 21 patients had acromio-clavicular joint dislocation (classified based on Sage and Salvatore type 3).

The inclusion criteria includes: 1) Type 3, 4, 5, and 6 acromioclavicular joint dislocations (Sage and Salvatore); 2) Type 2, 3 (Neer)-lateral end clavicle fractures.

The exclusion criteria includes patients with 1)previous history of periarthritis shoulder, rotator cuff lesion, and other shoulder pathology; 2) injuries involving superior suspensory shoulder ligament complex; 3) pediatric fractures; 4) open fractures.

\subsection{Operative Procedure}

Patient in beach chair position, under general anesthesia, incision is centered over distal end of clavicle, AC joint and curved posteriorly. The depth is measured between the posterior point of acromion and supraspinatus tendon as showed in Figure 1(a) and Figure 1(b). Three sizes of hook plates were 12, 15 and $18 \mathrm{~mm}$. Since in all patients, the distance between acromion and supraspinatus tendon measured was between $14-15 \mathrm{~mm}, 2$ to $3 \mathrm{~mm}$ lesser than measured depth hook plate was chosen - $12 \mathrm{~mm}$ plate was used as measured in Figure 2(a) and Figure 2(b). The hook is placed under the acromion. Full range of movements, forward flexion and abduction are tested. The plate is fixed to clavicle with three screws. There was no attempt to forcibly reduce the clavicle and to repair acromioclavicular and coracoclavicular ligaments.

\subsection{Post-Operative Care}

Patients were started on forward flexion, pendulum and 90 degree abduction exercises on first post op day. Gradually range of movements increased with full range of movements achieved at one month post-operatively as shown in Figure 3(a) and Figure 3(b). Patients undergo routine implant removal after 6 months of surgery.

\section{Results}

25 patients underwent the procedure from May 2010 to December 2015. On final follow up, none of the patients had impingement of supraspinatus tendon. 


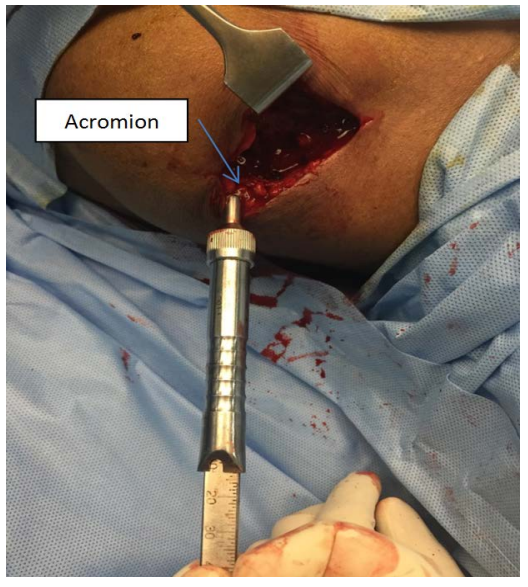

(a)

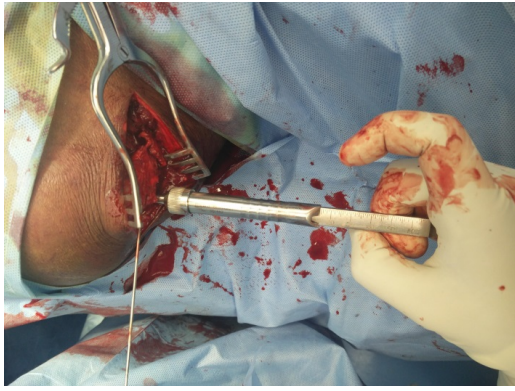

(b)

Figure 1. Intraoperative pictures: Distance between acromion and supraspinatus tendon measured using depth gauge.

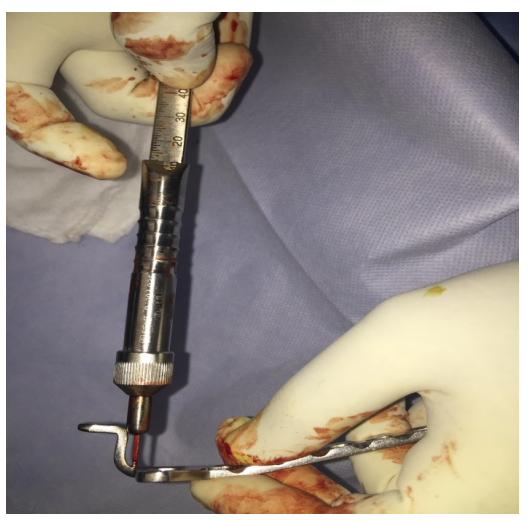

(a)

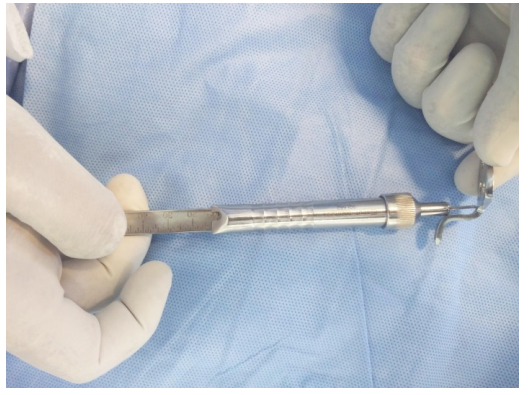

(b)

Figure 2. Depth of the hook in the clavicular hook plate measured with depth gauge.

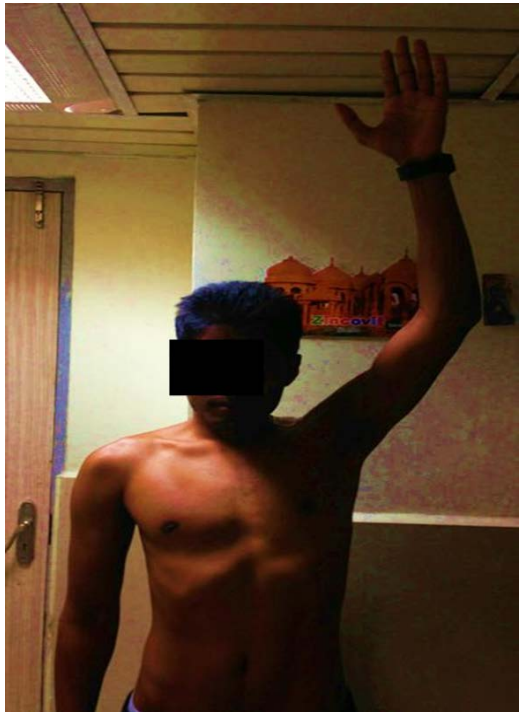

(a)

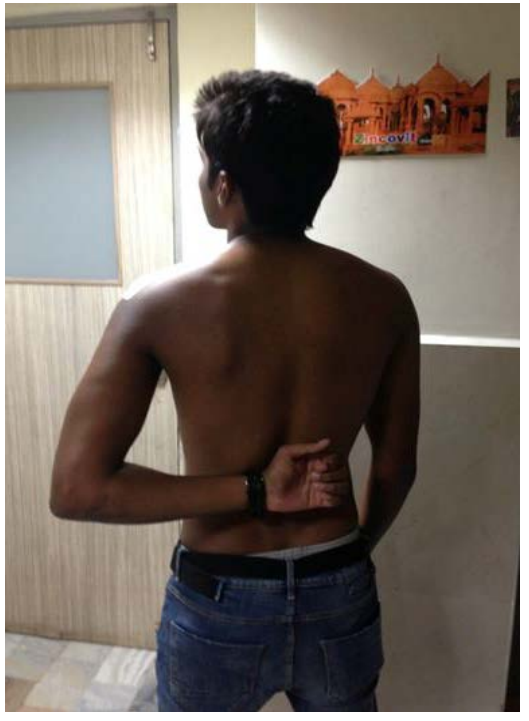

(b)

Figure 3. Clinical pictures of patient post operatively (A case of lateral end clavicle fracture treated with $12 \mathrm{~mm}$ clavicle hook plate). 
Five patients developed Sub acromial osteolysis which did not have any impact on shoulder function as shown in Table 1. Sub-acromial osteolysis resolved after plate removal.

\section{Discussion}

Type 1, type 2 acromioclavicular dislocations and undisplaced Neer type 1 lateral end clavicle fractures are treated conservatively with good results. The choice of

Table 1. Demographic data of patients.

\begin{tabular}{|c|c|c|c|c|c|c|}
\hline S. No & $\begin{array}{l}\text { Patient } \\
\text { sex }\end{array}$ & $\begin{array}{l}\text { Side of } \\
\text { injury }\end{array}$ & Injury sustained & $\begin{array}{c}\text { Depth } \\
\text { measured } \\
(\mathrm{mm})\end{array}$ & $\begin{array}{l}\text { Hook plate } \\
\text { used }(\mathrm{mm})\end{array}$ & Complications \\
\hline 1 & Male & Left & AC joint dislocation & 15 & 12 & $\begin{array}{c}\text { Subacromial } \\
\text { osteolysis }\end{array}$ \\
\hline 2 & Male & Left & Lateral end clavicle \# & 14 & 12 & Nil \\
\hline 3 & Male & Left & AC joint dislocation & 14.5 & 12 & Nil \\
\hline 4 & Female & Right & AC joint dislocation & 13 & 12 & Nil \\
\hline 5 & Male & Right & AC joint dislocation & 14 & 12 & Nil \\
\hline 6 & Male & Left & $\mathrm{AC}$ joint dislocation & 13 & 12 & Nil \\
\hline 7 & Female & Left & AC joint dislocation & 13 & 12 & $\begin{array}{c}\text { Subacromial } \\
\text { osteolysis }\end{array}$ \\
\hline 8 & Male & Left & AC joint dislocation & 15 & 12 & Nil \\
\hline 9 & Female & Right & Lateral end clavicle \# & 13 & 12 & Nil \\
\hline 10 & Female & Right & Lateral end clavicle \# & 14.5 & 12 & Nil \\
\hline 11 & Male & Left & $\mathrm{AC}$ joint dislocation & 13.5 & 12 & Nil \\
\hline 12 & Male & Right & $\mathrm{AC}$ joint dislocation & 13.5 & 12 & Nil \\
\hline 13 & Male & Right & AC joint dislocation & 14.5 & 12 & Nil \\
\hline 14 & Female & Left & AC joint dislocation & 14.5 & 12 & Nil \\
\hline 15 & Male & Left & AC joint dislocation & 14 & 12 & Nil \\
\hline 16 & Male & Right & AC joint dislocation & 15 & 12 & Nil \\
\hline 17 & Male & Right & AC joint dislocation & 15 & 12 & $\begin{array}{c}\text { Subacromial } \\
\text { osteolysis }\end{array}$ \\
\hline 18 & Female & Right & AC joint dislocation & 15 & 12 & Nil \\
\hline 19 & Female & Right & AC joint dislocation & 13 & 12 & Nil \\
\hline 20 & Male & Left & AC joint dislocation & 14 & 12 & Nil \\
\hline 21 & Male & Left & AC joint dislocation & 14 & 12 & Nil \\
\hline 22 & Female & Left & Lateral end clavicle \# & 13 & 12 & Nil \\
\hline 23 & Female & Left & $\mathrm{AC}$ joint dislocation & 13 & 12 & Nil \\
\hline 24 & Female & Left & $\mathrm{AC}$ joint dislocation & 13 & 12 & $\begin{array}{c}\text { Subacromial } \\
\text { osteolysis }\end{array}$ \\
\hline 25 & Male & Left & AC joint dislocation & 15 & 12 & Nil \\
\hline
\end{tabular}


fixation varies from $\mathrm{K}$ wire fixation, coracoclavicular screw fixation, lateral end plates, hook plate fixation and Weaver Dunn procedure for Neer 2, 3 clavicle fractures and type $3 \mathrm{AC}$ joint injuries (Figure $4(\mathrm{a})$ ). The relative rotatory movement of clavicle during abduction of shoulder causes failure of Kwire fixation and cancellous screw fixation. The clavicular hook plate is designed to fit anatomically to the acromion and clavicle, with the hook extending from the plate acting as a lever beneath the acromion as shown in Figure 4(b). The hook plate allows rotatory movements between acromion and clavicle [4]. The main concern with hook plates is that the plates may cause sub acromial shoulder impingement, sub acromial osteolysis [5] or even rotator cuff tear. This has been reported by many authors and it is related to hook plate design (depth of the hook). In our study, we sought to determine whether measuring the depth between acromion and supraspinatus tendon intraoperatively and fixing appropriate sized hook plates prevents the sub acromial shoulder impingement.

El Maraghy et al. demonstrated the mismatch between plate and sub acromial space and recommended $12 \mathrm{~mm}$ depth of hook for women. [6] In our study hook plate with smaller depth of $12 \mathrm{~mm}$ was used as the average depth between acromion and supraspinatus tendon was $15 \mathrm{~mm}$. Lee et al. performed arthroscopic procedure and hook plate of $12 \mathrm{~mm}$ size hook was used and none of the patients suffered impingement. [7] However 17\% of the patients had subacromial osteolysis. In a study by Siwei Sun, Minfeng Gan, Han Sun, Guizhong $\mathrm{Wu}, 26 \%$ of patients had sub acromial osteolysis [8]. The important cause for this complication is retaining the implant which resolves after implant removal. However it does not affect functional outcome. Fracture at medial end of plate is a complication reported due to small sized hook. This is due to forcible reduction of clavicle. Hence we did not do forcible reduction of clavicle in our patients.

Hsin Yu Din in his study measured the depth and used 15 and $18 \mathrm{~mm}$ hook plates and reported 37.5 (15 out of 40) patients with shoulder impingement. Ultrasonic evaluation for all the patients suggested hook plate impingement and rotator cuff lesion [3]. In our study $12 \mathrm{~mm}$ hook was used and no impingement

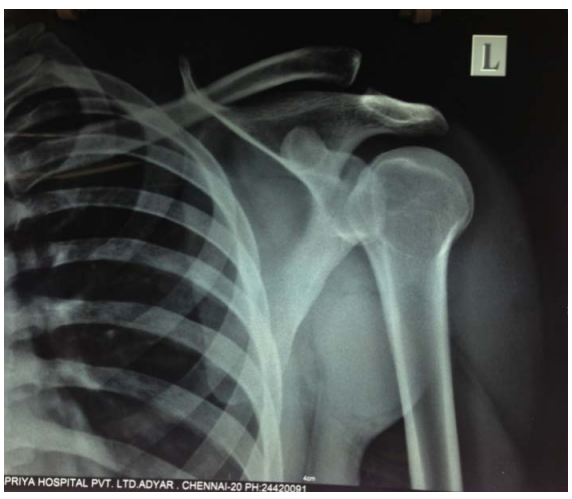

(a)

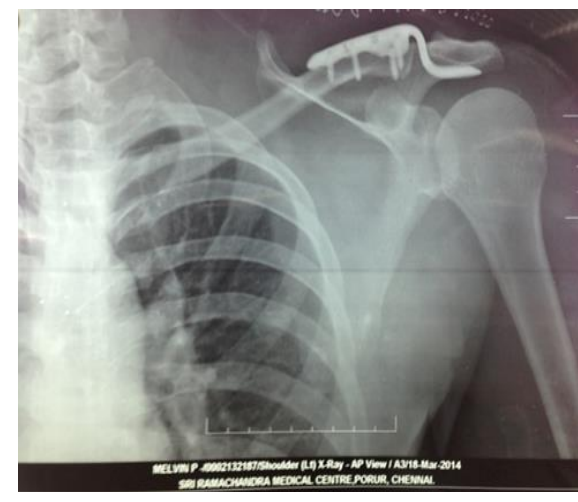

(b)

Figure 4. (a) and (b) show the pre op and post op x rays of a patient with AC joint dislocation, showing satisfactory reduction and fixation. 
was observed. However ultrasound evaluation was not done in our study. In $20 \%$ of patients, sub-acromial osteolysis was observed which subsided after implant removal.

The study also has some limitations. With a number of patients being small further cadaveric Studies are needed to estimate the hook depth and variation of acromion anatomy in South Asian population.

\section{Conclusion}

Operative treatment of AC joint dislocations and lateral end clavicle fractures gives good results with hook plate fixation. Impingement can be avoided by measuring the depth of acromion and supraspinatus tendon intraoperatively and using hook plate with appropriate depth.

\section{Recommendations}

1) Hook plate $15 \mathrm{~mm}$ and $18 \mathrm{~mm}$ used in western population may not suite South Asian population.

2) According to our study hook plate of smaller depth of $12 \mathrm{~mm}$ may prevent supraspinatus impingement.

\section{References}

[1] Chaudhary, D., Jain, V., Joshi, D., Jain, J.K., Goyal, A. and Mehta, N. (2015) Arthroscopic Fixation for Acromioclavicular Joint Disruption Using Tight Rope Device. Journal of Orthopaedic Surgery, 23, 309.

[2] Postacchini, F., Gumina, S., De Santis, P. and Albo, F. (2002) Epidemiology of Clavicle Fractures. Journal of Shoulder and Elbow Surgery, 2, 452-456.

[3] Lin, H.-Y., Wong, P.-K., Ho, W.-P., Chuang, T.-Y., Liao, Y.-S. and Wong, C.-C. (2014) Clavicular Hook Plate May Induce Subacromial Shoulder Impingement and Rotator Cuff Lesion-Dynamic Sonographic Evaluation. Journal of Orthopaedic Surgery and Research, 9, 6. https://doi.org/10.1186/1749-799X-9-6

[4] Senna, A.S.A. (2012) Hook Plate for Displaced Neer Type 2 Lateral End Clavicular Fractures. $A A M J$, 10, No. 3.

[5] Odak, S. and Burton, D. (2010) Early Acromial Erosion with the Syntheshookplate: An Unusual Complication and Its Treatment. Shoulder and Elbow.

[6] El Maraghy, A.W., Devereaux, M.W., Ravichandran, K. and Agur, A.M. (2010) Subacromial Morphometric Assessment of the Clavicle Hook Plate. Injury, 41, 613-619.

[7] Lee, K., Lee, S.K., Kim, K.J., Kim, Y.I., Kwon, W.C. and Choy, W.S. (2009) Arthroscopic Assisted Locking Compression Plate Clavicular Hook Fixation for Unstable Fractures of Lateral End of Clavicle: A Prospective Study. International Orthopaedics, 34, 839-845.

[8] Sun, S., Gan, M.F., Sun, H., Wu, G.Z., Yang, H.L. and Zhou, F. (2016) Does Subacromial Osteolysis Affect Shoulder Function after Clavicle Hook Plating? Biomed Research International, 2016, Article ID: 4085305. 
Submit or recommend next manuscript to SCIRP and we will provide best service for you:

Accepting pre-submission inquiries through Email, Facebook, LinkedIn, Twitter, etc. A wide selection of journals (inclusive of 9 subjects, more than 200 journals)

Providing 24-hour high-quality service

User-friendly online submission system

Fair and swift peer-review system

Efficient typesetting and proofreading procedure

Display of the result of downloads and visits, as well as the number of cited articles Maximum dissemination of your research work

Submit your manuscript at: http://papersubmission.scirp.org/

Or contact ojo@scirp.org 